\title{
Tobacco coverage in print media: the use of timing and themes by tobacco control supporters and opposition before a failed tobacco tax initiative
}

\author{
Jenine K Harris, ${ }^{1}$ Sarah C Shelton, ${ }^{2}$ Sarah Moreland-Russell, ${ }^{1}$ Douglas A Luke ${ }^{2}$
}

${ }^{1}$ Center for Tobacco Policy Research, Saint Louis University School of Public Health, St Louis Missouri, USA ${ }^{2}$ Center for Tobacco Policy Research, George Warren Brown School of Social Work, Washington University in St Louis, St Louis, Missouri, USA

\section{Correspondence to}

Jenine K Harris, Center for

Tobacco Policy Research, Saint Louis University School of Public Health, 3545 Lafayette Ave, Suite 300, St Louis, M0 63104, USA; harrisjk@slu.edu

Received 2 July 2009 Accepted 12 October 2009

Published Online First

3 December 2009

\section{ABSTRACT}

Objective Tobacco control policies gained ground nationwide in 2006, with voters in nine states approving legislation to strengthen clean indoor air policies and increase tobacco excise taxes. Despite having the second lowest cigarette tax rate in the nation, Missouri was unsuccessful in passing its 2006 ballot initiative to raise the tax. An important way to encourage healthrelated policy change such as increasing tobacco taxes is through media coverage of tobacco issues. We examined how tobacco issues were presented in Missouri's print media leading up to the 2006 election. Methods This study analysed 1263 articles with tobacco content published in 187 Missouri newspapers in the year before the election. Articles were coded for general and tobacco-related characteristics including article type (news story, editorial, letter to the editor), tobacco control position (pro, neutral, anti) and article theme (economic, health, political)

Results Most articles were news stories (73.6\%) and pro-tobacco control (63.8\%). The proportion of antitobacco control articles increased significantly $\left(\chi^{2}=104.9, p<0.001\right)$ the month before the election, driven by an increase in economically themed articles. Economic articles were published more often in counties with less voter support for the tax $(F=5.68, p<0.01)$. Finally, tobacco control position varied significantly across article types $\left(\chi^{2}=148.3, p<0.01\right)$, with letters to the editor being anti-tobacco control most often.

Conclusion The media have a critical role in promoting public health goals and presenting health issues which influences formation of health policies. Tobacco control advocates must consider public opinion, opposition pressure, timing and themes in tobacco-related media coverage when promoting policy change.

\section{INTRODUCTION}

Tobacco control policies gained ground nationwide during the 2006 election cycle, with voters in nine states-Arizona, Arkansas, Colorado, Hawaii, Louisiana, Nevada, New Jersey, Ohio and Utah, as well as the District of Columbia and Puerto Rico-approving legislation to strengthen clean indoor air policies and increase tobacco excise taxes. These state policy strategies have been shown to be among the most effective ways to reduce tobacco use-the leading cause of preventable death in the USA $^{1}$ - and follow the 20-year trend in state tobacco control strategies which increasingly target the social environment. ${ }^{2-6}$ Since 1988, 22 statewide ballot initiatives to raise the cigarette/tobacco tax have been sent to the voters of nine states. ${ }^{7}$ Eight of these initiatives have failed, including two introduced in 2006. ${ }^{7}$ Despite having one of the lowest cigarette tax rates in the nation, Missouri was one of the two unsuccessful states in 2006.

Garnering support for tobacco control policy is an important public health objective in states like Missouri, where $24.6 \%$ of adults, ${ }^{8} 23.8 \%$ of high school students ${ }^{9}$ and $18.3 \%$ of pregnant women ${ }^{10}$ are current smokers. While Missouri is not a tobacco-growing state, it has the fourth highest adult smoking rate 8 and the sixth highest lung and bronchus cancer incidence rate ${ }^{11}$ in the country. As of 2006, Missouri's cigarette excise tax ranked second lowest in the USA at $\$ 0.17$ per pack, ${ }^{1}$ and less than $1 \%$ of Missouri's population was covered by clean indoor air legislation. ${ }^{12}$ Currently, Missouri is still behind the curve in strengthening tobacco control policy with no change in the cigarette excise tax since $1993^{13}$ and just $13.3 \%$ of workers protected by smoke-free workplace policies. ${ }^{14}$

Media coverage of public health issues is an important way to encourage health-related policy change. ${ }^{15} 16$ Media advocacy plays a critical part in promoting public health goals ${ }^{17} 18$ and is an important component of comprehensive tobacco control programmes. ${ }^{151920}$ Furthermore, framing of health-related issues has a central role in successful public health policy advocacy, ${ }^{17}$ in particular in the formation of tobacco control policies. ${ }^{18}$

As tobacco control efforts increasingly emphasise policy-based strategies, it is important to understand how tobacco issues are presented in the media and how such presentation can influence policy outcomes. ${ }^{15} 18$ Studies have shown that the American public is interested in health-related news topics, especially those related to tobacco. ${ }^{21} \mathrm{Also}$, coverage of tobacco in news media tends to emphasise successes, lending support to tobacco control. $^{15}$ For example, one study of tobacco coverage in rural Kentucky found that articles about tobacco control were more prominent in communities where clean indoor air policy was being promoted. ${ }^{22}$ While media coverage can sometimes hinder the successful adoption of tobacco policies, ${ }^{23}$ it has played a part in the success of clean indoor air ordinances nationwide ${ }^{24}$ and in enacting international smoking control legislation. ${ }^{25} 26$ Previous studies have examined coverage of tobacco control issues in the media throughout Australia, ${ }^{19}$ Mexico $^{27}$ and the USA, ${ }^{15} 182021$ including print media coverage of the smoke-free bar law in California $^{28}$; the effects of a clean indoor air campaign on media coverage of tobacco in Kentucky ${ }^{22}$; and the effects of a media campaign on tobacco use in 
Texas. ${ }^{29}$ However, other than the Kentucky study, no studies have analysed the print media coverage of, and framing of, tobacco issues in a state such as Missouri, with its challenging tobacco control environment.

This study analyses the coverage of tobacco issues in Missouri's print media during the year leading up to the 2006 general election. This election included a ballot issue to increase the tobacco excise tax by 80 cents per pack of cigarettes and $20 \%$ on other tobacco products. Had the tax passed it would have increased Missouri's tax to be in line with the average state cigarette tax in the USA at the time. Specifically, we examine: (1) the overall position of the news articles, editorials and letters to the editor (ie, pro, anti or neutral to tobacco control), (2) themes related to how tobacco messages were presented in the print media (using health, economic and political arguments), (3) how article position and themes changed over time, and (4) how article position and themes were associated with voter support for the tax increase. The results of this study provide important information relating to the timing, placement and themes of tobacco coverage in media. This information will aid tobacco control professionals in effectively planning to use media to combat anti-tobacco influences, advance tobacco control efforts and promote policy change.

\section{METHODS}

\section{Print media data collection}

In 2004 the Missouri Foundation for Health funded a 9-year initiative aimed at reducing tobacco use in Missouri. In partnership with other regional and national tobacco control organisations, organisers developed 'Show Me Health: Clearing the Air About Tobacco'. One of the 'Show Me Health' strategies was to develop and implement an educational campaign regarding the impact of tobacco use in Missouri. Although the campaign did not directly advocate for a tobacco tax increase, increased awareness of tobacco's toll in Missouri was expected to bolster support for the ballot initiative. As part of the 'Show Me Health' evaluation, the Center for Tobacco Policy Research (CTPR) worked with Metropolitan News Clips Service, Inc, to monitor the coverage of tobacco issues in all 446 daily and weekly Missouri newspapers published in 90 counties during the year leading up to the 2006 general election. These papers included major city dailies with circulation over $100 \mathrm{k}$ (eg, the St Louis PostDispatch) and smaller suburban and rural newspapers (eg, the Boone County Journal).

\section{Measures and analysis}

To analyse the tobacco-related content of these articles, CTPR developed a 24-item codebook based on similar public health content analysis studies. ${ }^{18} 202830$ Each article was coded for general information about the newspaper and story (eg, county of publication, date of publication, name of newspaper), for the article type (ie, news story, editorial or letter to the editor), for tobacco related topic(s) mentioned in the article (ie, youth prevention, adult cessation, smoke-free policies, tobacco taxes and tobacco science), and for the overall position of the article (ie, anti-tobacco control, neutral or pro-tobacco control).

An article was coded as pro-tobacco control or anti-tobacco control if the text included information that supported or opposed tobacco cessation and prevention efforts, respectively. For example, one news story coded as anti-tobacco control stated, "Attorney General Jay Nixon opposes a ballot initiative that would raise taxes on cigarettes and devote money to health care providers and anti-smoking efforts" (Nixon opposes proposal to raise cigarette tax, St Louis Post-Dispatch, 4/16/06). In contrast, a pro-tobacco control news story stated, "A judge ruled Monday that supporters of a state tobacco tax had gathered enough signatures to place the measure on the November ballot. Cole County Circuit Judge Thomas Brown overturned a decision more than a month ago that the amendment had fallen nearly 300 names shy of the required mark in the Kansas City Area" (Judge orders tobacco tax on Missouri's November Ballot, Cape Girardeau Southeast Missourian, 9/12/06). If the information in the article was balanced in the amount of information presented for and against tobacco control, or if an article presented no opinion regarding tobacco control, it was coded as neutral.

Articles were also coded for the dominant theme by identifying specific arguments about tobacco control and about a tobacco tax increase. The 24 arguments fell into three categories: health, economic and political (table 1). Health arguments were those that conveyed general health consequences of tobacco use, the addictive nature of tobacco or the behavioural effect of a tobacco tax increase on tobacco use. Economic arguments conveyed monetary reasons for or against a tobacco tax increase, particularly at the societal level. Political arguments conveyed ideological reasons for or against a tobacco tax increase. Each article may have been coded for numerous arguments; the dominant theme of the article was the category (health, economic or political) represented by the most arguments in each article (eg, an article with four health arguments and one economic argument has a dominant health theme). Several arguments identified in this study have been seen in other statewide campaigns. ${ }^{7}$ For example, the health argument, "The tax will increase prevention/cessation among youth" was used by proponents of cigarette tax increases in more than half of the 22 statewide initiatives since 1988. The political argument, "It's a regressive tax" was used by tobacco control opposition in 15 campaigns and the economic argument, "The revenue from the tax will not be enough to cover the promised services" was used by the opposition in seven campaigns.

After removing 18 articles from the dataset that were either incomplete, from an out-of-state newspaper or contained no tobacco content, three trained coders coded a total of 1263 articles. To ensure reliability of the coding process, each article was coded by two of the three coders. We calculated percentage agreement and Brennan and Prediger's $\kappa^{31}$ to determine the reliability of the coding process. Variables had the following percentage agreement and $\kappa$ scores: article type $(93.7 \%$; $\kappa=0.91)$; article position $(62.7 \%$; $\kappa=0.44)$; tobacco topics $(91.4 \%-98.5 \%$; $\kappa=0.83-0.97)$; arguments $(78.6 \%-99.8 \%$; $\kappa=0.57-0.99)$ (see table 1). According to standard interpretations of $\kappa$, most of the coding resulted in substantial $(\kappa=0.61-0.80)$ or nearly perfect agreement $(\kappa>0.80)$ between coders. When a pair's codes differed, a fourth trained coder resolved the disagreement.

In addition to the media data, voting outcome data from the Missouri Secretary of State Election Result Archives (http:// www.sos.mo.gov/enrweb/electionselect.asp?eid=203) were also used. We employed standard descriptive and inferential statistics to explain basic characteristics of the print media, examine associations among article characteristics (eg, position, dominant theme) and determine whether there was an association between voting patterns and media content. We used $\chi^{2}$ to determine associations between categorical variables. Where there were significant associations we examined a contingency table including standardised residuals to determine what was driving the significant result. Standardised residuals convert the difference between the observed value and expected value into a $z$ score. Standardised residuals larger than two, therefore, indicate 
Table 1 Tobacco control theme categories and arguments

\begin{tabular}{|c|c|c|c|c|}
\hline $\begin{array}{l}\text { Dominant } \\
\text { theme }\end{array}$ & Argument & $\begin{array}{l}\text { Number of } \\
\text { arguments }\end{array}$ & $\begin{array}{l}\% \text { arguments } \\
\text { by theme }\end{array}$ & $\begin{array}{l}\text { Brennan and } \\
\text { Prediger's } \kappa\end{array}$ \\
\hline \multirow[t]{10}{*}{ Economic } & $\begin{array}{l}\text { Tax will pay for other health-related } \\
\text { programmes }\end{array}$ & 501 & $29 \%$ & 0.83 \\
\hline & $\begin{array}{l}\text { The tax will pay for tobacco prevention } \\
\text { and cessation programmes }\end{array}$ & 478 & $28 \%$ & 0.84 \\
\hline & $\begin{array}{l}\text { The tax will raise general revenue for the } \\
\text { state }\end{array}$ & 357 & $21 \%$ & 0.82 \\
\hline & $\begin{array}{l}\text { States don't spend enough money on } \\
\text { tobacco control and prevention; there } \\
\text { needs to be an increase in dollars for } \\
\text { tobacco control and prevention }\end{array}$ & 79 & $5 \%$ & 0.86 \\
\hline & $\begin{array}{l}\text { The tax will recover medical expenses } \\
\text { associated with tobacco-related disease }\end{array}$ & 76 & $4 \%$ & 0.88 \\
\hline & $\begin{array}{l}\text { The tax money may not go where its } \\
\text { intended (eg, MSA funding } \\
\text { misappropriation) }\end{array}$ & 74 & $4 \%$ & 0.90 \\
\hline & $\begin{array}{l}\text { The revenue from the tax will not be } \\
\text { enough to cover the promised services } \\
\text { (unfunded mandate) }\end{array}$ & 67 & $4 \%$ & 0.92 \\
\hline & A smoking ban hurts/will hurt businesses & 52 & $3 \%$ & 0.93 \\
\hline & The tax will hurt businesses & 48 & $3 \%$ & 0.97 \\
\hline & Should tax those who smoke & 44 & $3 \%$ & 0.91 \\
\hline \multirow[t]{7}{*}{ Health } & $\begin{array}{l}\text { Tobacco use leads to negative health } \\
\text { consequences }\end{array}$ & 383 & $33 \%$ & 0.57 \\
\hline & Concerned about secondhand smoke & 235 & $20 \%$ & 0.69 \\
\hline & $\begin{array}{l}\text { Increasing the cigarette tax is a way to } \\
\text { decrease tobacco use }\end{array}$ & 173 & $15 \%$ & 0.82 \\
\hline & $\begin{array}{l}\text { The tax will increase prevention/cessation } \\
\text { among youth }\end{array}$ & 138 & $12 \%$ & 0.86 \\
\hline & $\begin{array}{l}\text { Tobacco use by individual or family } \\
\text { member/friend }\end{array}$ & 118 & $10 \%$ & 0.82 \\
\hline & $\begin{array}{l}\text { Tobacco use is addictive; people cannot } \\
\text { help it }\end{array}$ & 96 & $8 \%$ & 0.85 \\
\hline & $\begin{array}{l}\text { Raising taxes will have no effect on } \\
\text { tobacco use }\end{array}$ & 24 & $2 \%$ & 0.95 \\
\hline \multirow[t]{8}{*}{ Political } & Tobacco use is a personal choice/freedom & 103 & $27 \%$ & 0.89 \\
\hline & The tobacco industry deceived us & 66 & $18 \%$ & 0.91 \\
\hline & It's not fair to tax a certain group of people & 65 & $17 \%$ & 0.91 \\
\hline & $\begin{array}{l}\text { Taxes are high enough; taxes in general } \\
\text { should not be increased }\end{array}$ & 57 & $15 \%$ & 0.90 \\
\hline & It's a regressive tax & 45 & $12 \%$ & 0.97 \\
\hline & $\begin{array}{l}\text { There are problems that need to be } \\
\text { addressed other than tobacco use }\end{array}$ & 20 & $5 \%$ & 0.96 \\
\hline & Tobacco use is legal & 16 & $4 \%$ & 0.97 \\
\hline & $\begin{array}{l}\text { Should not punish people who are } \\
\text { addicted to tobacco }\end{array}$ & 4 & $1 \%$ & 0.99 \\
\hline
\end{tabular}

large differences between observed values and expected values that drive a significant $\chi^{2}$ result. Finally, we used ANOVA to compare the mean percentage of people in favour of the tax across categories including publication month, dominant theme and article position.

\section{RESULTS \\ Characteristics of tobacco coverage in the print media before Missouri's 2006 tobacco tax initiative election}

The 1263 tobacco-related articles identified by the clipping service were published between 1 September 2005 and 6 December 2006 in 187 (42\%) of Missouri's 446 newspapers. There were 930 news stories (73.6\%), 191 letters to the editor $(15.1 \%)$ and 142 editorials (11.2\%). Most articles were about tobacco tax policies (54.8\%) and took a pro-tobacco control position (63.8\%). The number of articles published increased significantly over time $(r=0.67 ; \mathrm{p}<0.01)$, with 215 (17\%) being published in October 2006, the final month before the election.
Article positions regarding tobacco control

Articles were classified as anti-tobacco control (12.6\%), neutral (23.6\%) or pro-tobacco control (63.8\%). There was a significant difference in the article position across the three article types $\left(\chi^{2}=148.3, \mathrm{df}=4, \mathrm{p}<0.01\right)$. We conducted residual analysis to identify what was driving this significant result. Letters to the editor and editorials were more likely than expected to be antitobacco control, while news stories were less likely than expected to be anti-tobacco control. Additionally, observed frequencies were lower than expected for neutral letters to the editor and higher than expected for news stories. (figure 1).

The number of tobacco-related articles increased sharply the month preceding the general election (ie, October 2006). Concurrent with the increase in the number of articles was a shift in the mix of pro-tobacco control, neutral and anti-tobacco control articles. Specifically, the proportion of articles taking a neutral or anti-tobacco control position increased in the month before the election while the proportion of articles taking a pro-tobacco control position decreased during this time (figure $2 \mathrm{a}$ ). A $\chi^{2}$ analysis 


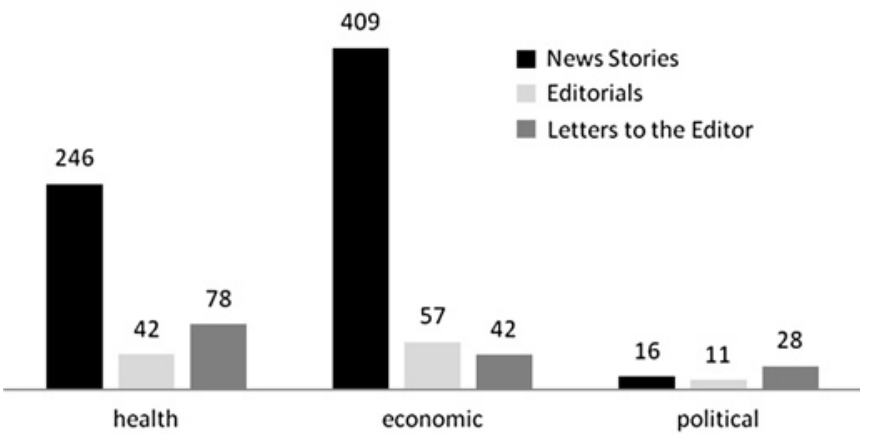

b Number of articles of each type with each position

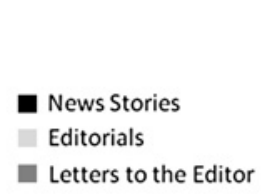

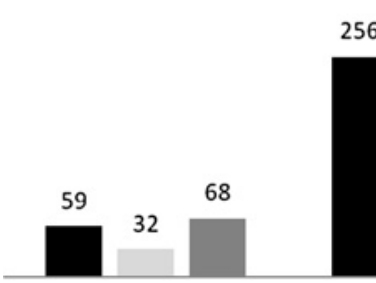

anti

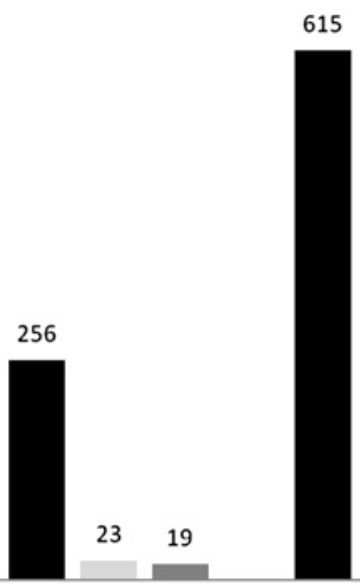

neutral

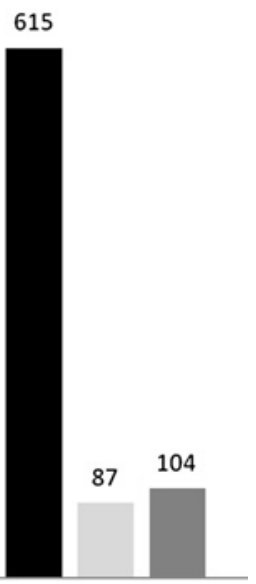

pro
Figure 1 Dominant theme and position of letters to the editor, news stories and editorials.

of publication month and article position identified a significant association $\left(\chi^{2}=104.9, \mathrm{df}=30, \mathrm{p}<0.001\right)$. Standardised residuals showed the decrease in pro-tobacco control articles and the increase in anti-tobacco control articles in October and November 2006 drove the significant $\chi^{2}$ results.

\section{Article themes}

Overall, the 1263 articles contained 1724 economic arguments, 1167 health arguments and 326 political arguments, for a total of 3267 occurrences of the 24 arguments (table 1). Twenty-nine per cent of articles $(n=366)$ had a dominant health theme, $40.2 \%$ $(\mathrm{n}=508)$ had a dominant economic theme and $4.4 \%(\mathrm{n}=55)$ had a dominant political theme. Over a quarter $(27 \% ; n=334)$ of articles had no dominant theme; most of these were articles that did not include one of the 24 arguments ( $n=239)$, while some had equal numbers of arguments in more than one category $(n=95)$.

\section{Dominant theme and article type}

We found a significant association between dominant article theme and article type $\left(\chi^{2}=91.2, \mathrm{df}=4, \mathrm{p}<0.01\right)$. Residual analysis indicated the significant $\chi^{2}$ results were driven by letters to the editor and news stories. Letters to the editor were more likely than expected to have a dominant political or health theme and less likely to have an economic theme. News stories, on the other hand, were more likely than expected to have a dominant economic theme and less likely to have a political theme.

\section{Article themes and timing}

While the number of tobacco-related articles increased overall during the few months preceding the general election a Proportion of all articles taking each tobacco control position over time
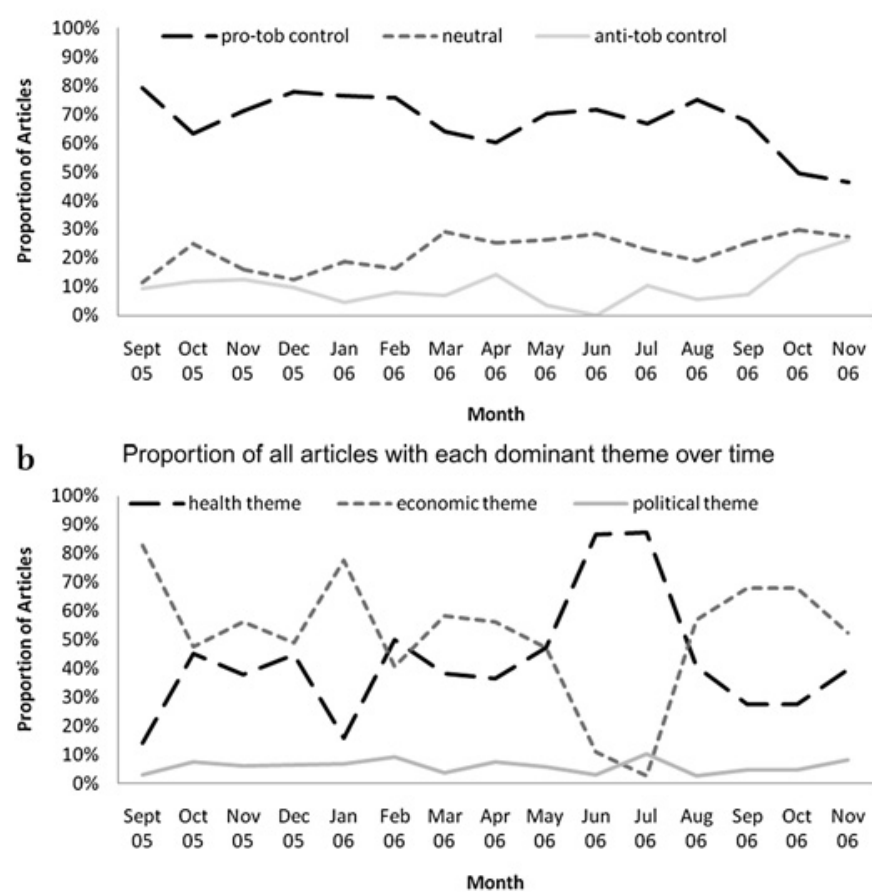

Figure 2 Trends in article position and dominant theme before the November 2006 election.

(ie, May 2006 through October 2006), the number of articles with a dominant economic theme increased more than the number of articles with political or health themes (sixfold compared to fivefold and threefold, respectively). Figure $2 b$ shows the proportion of articles with each dominant theme over time. $\chi^{2}$ analyses found significant differences $(p<0.05)$ in the proportion of articles with each of the three dominant themes at different times throughout the year. While the proportion of articles with a dominant political theme stayed relatively consistent over time, residuals indicated a greater proportion of articles than expected with dominant health themes in summer 2006 and a smaller than expected proportion of articles with a dominant health theme in autumn 2006 , closer to the election. In addition, there were fewer than expected economic articles in summer 2006, but economic coverage was higher in the autumn of 2006 , just before the election.

Relations between dominant article theme, position and timing We found that there was a significant association between dominant theme and article positions $\left(\chi^{2}=262.9, \mathrm{df}=4, \mathrm{p}<0.01\right)$. Standardised residuals indicated that there were more protobacco control articles with a dominant health theme and anti-tobacco control articles with a dominant political theme than expected. Observed frequencies were lower than expected for neutral and anti-tobacco control health articles, neutral economic articles and pro-tobacco control political articles.

In order to determine whether articles with specific dominant themes and positions were published closer to the election, we conducted a 3-by-3 factorial ANOVA with dominant theme and position as independent variables and month of publication as the dependent variable. We found significant differences $(F=7.20, \mathrm{df}=8, \mathrm{p}<0.01)$ in the average month of publication for articles with each position and theme. While there were no significant main effects for theme $(\mathrm{F}=1.84, \mathrm{df}=2, \mathrm{p}=0.16)$ or position $(\mathrm{F}=2.84, \mathrm{df}=2, \mathrm{p}=0.06)$ the interaction term theme-byposition was significant $(\mathrm{F}=2.55, \mathrm{df}=4, \mathrm{p}=0.04)$. Figure 3 sheds 
light on the issue of timing, showing a distinct increase in neutral and anti-tobacco control economic articles in the month before the election.

\section{Voting patterns and coverage of tobacco issues in the print media}

The percentage of voters who voted in favour of the tax ranged from a low of $30.5 \%$ in two counties in southeast Missouri (Washington, Reynolds) to a high of $56.6 \%$ in St Louis County, with overall support of $48 \%$ of Missourians who voted. Of the 115 areas, eight counties, including the two densely populated urban areas of St Louis City and Jackson County, approved the tobacco tax initiative with over $50 \%$ of votes in support.

We conducted a 3-by-3 factorial ANOVA to determine whether voter support for the tax was associated with dominant article theme and position. Voter support was the dependent variable and position and theme were the independent variables in this model. We found significant differences $(F=5.68$, $\mathrm{df}=8, \mathrm{p}<0.01$ ) in mean percentage of voter support (figure 4). Specifically, articles with economic themes were published in counties with the lowest percentages of the vote in favour of the $\operatorname{tax}(\mathrm{m}=46-48 \%)$ regardless of whether the article was protobacco control, neutral or anti-tobacco control. Articles with health and political themes, on the other hand, were published in counties with higher average voter support $(m=48-54 \%)$ for the tobacco tax. Interestingly, articles with anti-tobacco control

a Number of pro-tobacco control articles by theme over time

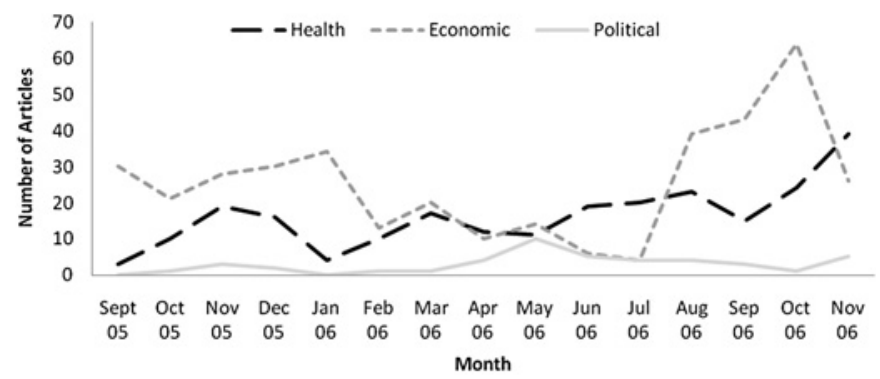

b Number of neutral articles by theme over time

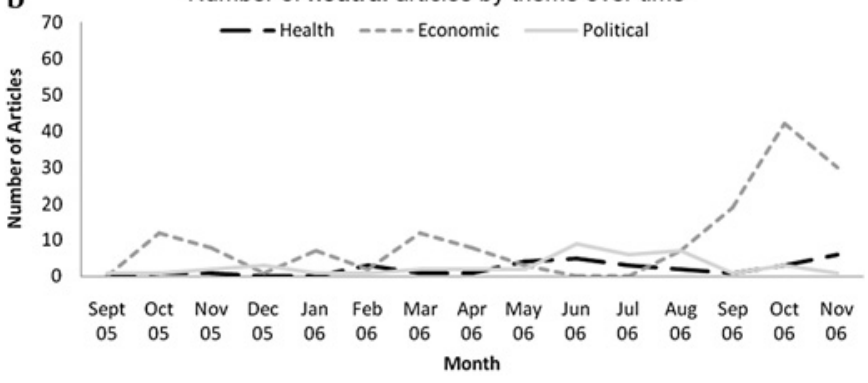

C Number of anti-tobacco control articles by theme over time

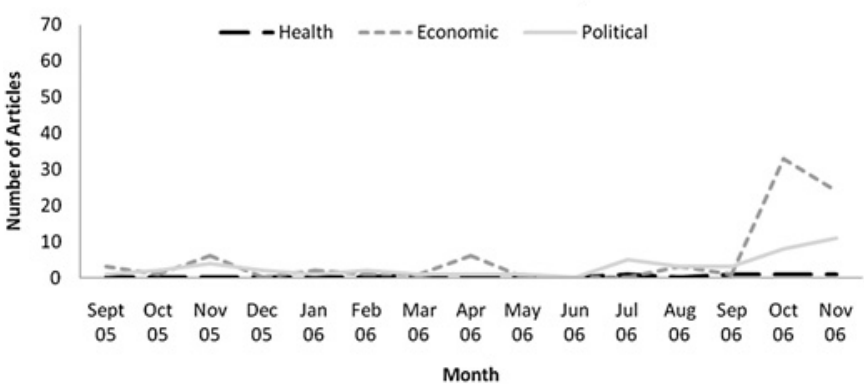

Figure 3 Neutral and anti-tobacco control economic articles surged just prior to the November 2006 election.

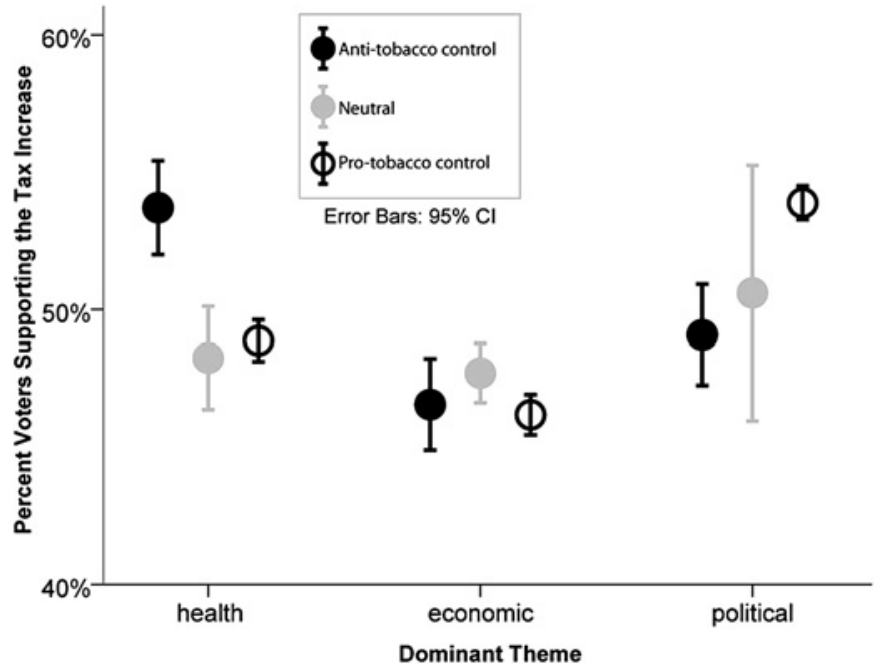

Figure 4 Mean percent of voters supporting the tax by article theme and position in the county where the article was published.

positions and dominant health themes were published in counties with higher voter support for the tax than other articles with dominant health themes. This may point to some strategic opposition in counties with greater support for the tax.

\section{DISCUSSION}

As our analysis suggests, there are important lessons to be learnt by examining media coverage of health topics around health policy campaigns. We conducted an analysis of 1263 tobaccorelated articles published in 187 newspapers across 90 Missouri county areas in the year leading up to the 2006 statewide election in Missouri. This election was important for tobacco control in Missouri owing to a cigarette excise tax increase of 80 cents on the ballot. Had this initiative passed, it would have been the first increase since 1993 in the Missouri state cigarette tax, which ranks second to the lowest in the country. Our findings point to a number of hurdles faced by the pro-tobacco control movement during this year. First, while a majority of articles were pro-tobacco control throughout the year, there was a significant increase in the proportion of articles that took an anti-tobacco control position in the month preceding the election. Second, the increase in neutral and anti-tobacco control articles in the month preceding the election was driven by an increase in economically themed articles. Finally, compared to articles with dominant health or political themes, articles with economic themes were published more often in counties with less voter support for the tax initiative.

Secondary findings indicated that the public may have held different beliefs than the press about the tobacco tax and tobacco control. Specifically, there were significantly more letters to the editor taking an anti-tobacco control position than there were editorials or news stories taking an anti-tobacco control position. In addition, letters to the editor were more likely to have a dominant political theme and less likely to use an economic or health theme than other types of articles.

A number of these findings are consistent with past research. For example, a 2001 study by Durant and colleagues ${ }^{32}$ found that tobacco issues become more newsworthy at certain times and in certain places. Another study found that tobacco stories covered in the media are generally pro-tobacco control. ${ }^{33} \mathrm{Also}$, Harwood et al found that media attention to public health issues can decrease policy adoption. ${ }^{23}$ While the Harwood et al study 


\section{What is already known about this topic}

Media coverage of public health issues is an important way to encourage health-related policy change. The public is interested in health-related news topics, especially those related to tobacco, and the coverage of tobacco in news media tends to emphasise successes and to lend support to tobacco control. Media coverage has played a part in the success of clean indoor air ordinances nationwide and in enacting international smoking control legislation.

focused on legislative processes of policy adoption, our study findings are similar in that increased media coverage of a particular theme (economic) led to decreased voter support.

In addition to confirming previous studies, our findings point to the strategic use of timing and themes by those in opposition to the tobacco tax initiative. Backed by the tobacco industry, two main groups, the Missouri Petroleum Marketers and Convenience Stores Association and Missourians Against Tax Abuse, took advantage of the inability of pro-tax advocates to develop and widely disseminate a clear and consistent pro-tobacco control message. ${ }^{34}$ While there are certainly many factors contributing to the voting patterns, the last-minute increase in opposition using primarily economic themes was an effective tool in countering the tax initiative. In the final evaluation report of the 'Show Me Health' initiative, ${ }^{35}$ CTPR identified evidence of economic messaging being used by opposition to the tax increase. Specifically, one 'Show Me Health' message disseminated during the campaign, "For the past six years, Missouri has spent $\$ 0$ in state funds for a comprehensive tobacco use prevention and cessation programme, ranking us last in the country, although it has received over $\$ 1$ billion in Master Settlement payments" was repeatedly used by the opposition.

Also important was the finding related to the difference between the Missouri public and the press. In this study, letters to the editor appear different from editorials and news stories in several ways including taking a more anti-tobacco control position and using political arguments. News stories and editorials are most often written by newspaper staff, while letters to the editor are written by the general public (and selected by newspaper staff) and are thought to be an indicator of community sentiment. ${ }^{33}$ These differences indicate a disparity between Missouri citizens and media when it comes to tobacco issues.

There were several limitations of this study. First, our analysis is limited to print media coverage of tobacco issues. Print media are only one of many types of media that might affect public opinion. Second, a large percentage $(44.7 \%)$ of the articles collected and analysed were from the St Louis and Kansas City areas, the two most densely populated Missouri urban counties. While these counties were supportive of the tobacco control policies, when we explored the data we found no significant differences in the proportion of articles with pro-tobacco, neutral or anti-tobacco control positions in these areas compared with the rest of the state $\left(\chi^{2}=0.04, d f=2, p=0.98\right)$. Finally, our findings represent only a snapshot of how print media covered tobacco-related issues over the course of 1 year. Because adoption of tobacco control policies including clean air legislation and excise tax increases in Missouri is still met with strong resistance, it is important to examine media coverage over an extended period of time to measure its influence as part of comprehensive tobacco control efforts.

\section{What this study adds}

This study demonstrates the use of timing and themes related to tobacco issues in the print media by tobacco control proponents and opposition before a failed ballot initiative to increase a state tobacco tax. Tobacco control opposition use of economic arguments and an increase in anti-tobacco control articles in the month before the election, along with a notable difference between media coverage and citizen opinion seen in letters to the editor, confirm the need for tobacco control advocates to revisit media strategies when working to promote policy change.

\section{Conclusion and recommendations}

Strengthening tobacco policy, including raising state tobacco taxes, remains one of the best ways to reduce tobacco use. ${ }^{1-6}$ While ballot initiatives to raise tobacco taxes have been successful in several states, other states, including Missouri, have failed. $^{7}$ The media have a critical role in promoting public health goals and presenting health issues which influence the formation of tobacco control policies including raising state tobacco taxes. It is therefore essential for tobacco control professionals to understand how tobacco issues are presented in the media. In this study we identified several important characteristics of media coverage of tobacco in Missouri in the year leading up to the failed 2006 tobacco tax initiative. The following lessons learnt may be useful for tobacco control practitioners working to promote tobacco control policy: (1) prepare for significant increases of opposition in the final weeks before a policy event, (2) carefully consider how economic arguments may be interpreted by the public, and (3) track community sentiment expressed in letters to the editor, as this may be a better indicator of the level of support for tobacco control than news articles or editorials. More generally, it is important for tobacco control advocates to consider public opinion, opposition pressure, timing and themes in tobacco-related media coverage when promoting tobacco tax increases and other tobacco policy change in a challenging tobacco control climate.

Acknowledgements Funding for this project was provided in whole by the Missouri Foundation for Health. The Missouri Foundation for Health is a philanthropic organisation whose vision is to improve the health of the people in the communities it serves.

Contributors We would like to acknowledge Tanya Montgomery, Nancy Mueller, and Sarah Schell for their roles in this project, and Peg Allen, Bobbi Carothers, Elisia Cohen, Charlene Caburnay, and several additional members of the CTPR team for their comments on earlier draughts of this manuscript.

Funding Missouri Foundation for Health, 1000 Saint Louis Union Sta \#4, St. Louis, M0, 63103-2269, (314)-345-5500.

Competing interests There are no competing interests.

Provenance and peer review Not commissioned; externally peer reviewed.

\section{REFERENCES}

1. American Lung Association. State of tobacco control 2006. New York, NY, Washington DC, 2006

2. Centers for Disease Control and Prevention. Best practices for comprehensive tobacco control programs - 2007. Atlanta, GA: Centers for Disease Control and Prevention, 2007.

3. Levy DT, Hyland A, Higbee $C$, et al. The role of public policies in reducing smoking prevalence in California: results from the California tobacco policy simulation model. Health Policy 2007;82:167-85.

4. Liang L, Chaloupka F, Nichter M, et al. Prices, policies and youth smoking, May 2001. Addiction 2003;98(suppl 1):105-22. 
5. Stillman FA, Hartman AM, Graubard BI, et al. Evaluation of the American Stop Smoking Intervention Study (ASSIST): a report of outcomes. J Natl Cancer Inst 2003;95:1681-91.

6. Tauras JA. Public policy and smoking cessation among young adults in the United States. Health Policy 2004;68:321-32.

7. Lum KL, Barnes RL, Glantz SA. Enacting tobacco taxes by direct popular vote in the United States: lessons from 20 years of experience. Tob Control. 2009;18:377-86.

8. Centers for Disease Control and Prevention (CDC). State-specific prevalence and trends in adult cigarette smoking-United States, 1998-2007. MMWR Morb Mortal Wkly Rep 2009;58:221-6.

9. Brener ND, Kann L, Garcia D, et al. Youth risk behavior surveillance-selected steps communities, 2005. MMWR Surveill Summ 2007;56:1-16.

10. Nishimura BK, Adams EK, Melvin CL, et al. Prenatal smoking data book: state highlights. Atlanta, GA: Centers for Disease Control and Prevention, 2005.

11. U.S. Cancer Statistics Working Group. United States Cancer Statistics: 19992005 Incidence and Mortality Web-based Report. Atlanta: U.S. Department of Health and Human Services, Centers for Disease Control and Prevention and National Cancer Institute; 2009

12. Americans for Nonsmokers Rights. Percent of US state populations covered by 100\% smokefree air laws. 2006 http://www.no-smoke.org/pdf/percentstatepops.pdf (accessed 6 Aug 2009).

13. Campaign for Tobacco Free Kids. State cigarette excise tax rates and rankings 2009 http://www.tobaccofreekids.org/research/factsheets/pdf/0097.pdf laccessed 6 Aug 2009).

14. Americans for Nonsmokers Rights. Percent of US state populations covered by 100\% smokefree air laws. 2009 http://www.no-smoke.org/pdf/percentstatepops.pdf (accessed 6 Aug 2009)

15. Smith KC, Wakefield M, Edsall E. The good news about smoking: how do US newspapers cover tobacco issues? J Public Health Policy 2006;27:166-81.

16. Sato H. Agenda setting for smoking control in Japan, 1945-1990: influence of the mass media on national health policy making. J Health Commun 2003;8:23-40.

17. Wallack L, Dorfman L. Media advocacy: a strategy for advancing policy and promoting health. Health Educ 0 1996;23:293-317.

18. Menashe CL, Siegel M. The power of a frame: an analysis of newspaper coverage of tobacco issues-United States, 1985-1996. J Health Commun 1998:3:307-25.

19. Smith KC, Terry-McElrath Y, Wakefield M, et al. Media advocacy and newspaper coverage of tobacco issues: a comparative analysis of 1 year's print news in the United States and Australia. Nicotine Tob Res 2005;7:289-99.
20. Smith KC, Wakefield M. Textual analysis of tobacco editorials: how are key media gatekeepers framing the issues? Am J Health Promot 2005;19:361-8.

21. Brodie M, Hamel EC, Altman DE, et al. Health news and the American public, 1996-2002. J Health Polit Policy Law 2003:28:927-50.

22. Hahn E, Helme D, Lee E, et al. Rural print media portrayal of secondhand smoke and smoke-free policy. Poster presentation at the National Conference on Tobacco or Health, Phoenix (AZ), 2009

23. Harwood EM, Witson JC, Fan DP, et al. Media advocacy and underage drinking policies: a study of Louisiana news media from 1994 through 2003. Health Promot Pract 2005;6:246-57.

24. National Institutes of Health. Major Local Tobacco Control Ordinances in the United States. Report 93-3532. 1993. http://openlibrary.org/b/OL14453017M/ Major_local_tobacco_control_ordinances_in_the_United_States.

25. Chapman $\overline{\mathbf{S}}$. The role of advocacy in influencing government policy on tobacco. Lung Cancer 1993:9:29-34.

26. Jacobson PD, Wasserman J, Raube K. The politics of anti-smoking legislation. $J$ Health Polit Policy Law 1993:18:787-819.

27. Llaguno-Aguilar SE, Dorantes-Alonso AD, Thrasher JF, et al. Analysis of coverage of the tobacco issue in Mexican print media. Salud Publica Mex 2008;50:S348-54.

28. Magzamen S, Charlesworth A, Glantz SA. Print media coverage of California's smokefree bar law. Tob Control 2001;10:154-60.

29. McAlister A, Morrison TC, Hu SH, et al. Media and community campaign effects on adult tobacco use in Texas. J Health Commun 2004:9:95-109.

30. Helme DW, Borland R, Young W, et al. The development and validation of a coding protocol to measure change in tobacco-control newspaper coverage. Health Promot Pract 2006; 7:103-9.

31. Brennan RL, Prediger DJ. Coefficient kappa: some uses, misuses, and alternatives Educ Psychol Meas 1981:41:687-99.

32. Durrant R, Wakefield M, McLeod K, et al. Tobacco in the news: an analysis of newspaper coverage of tobacco issues in Australia, 2001. Tob Control 2001;12 (Suppl 2):ii75-81.

33. Smith KC, McLeod K, Wakefield M. Australian letters to the editor on tobacco: triggers, rhetoric, and claims of legitimate voice. Qual Health Res 2005;15:1180-98.

34. Center for Tobacco Policy Research. Committee for a healthy future amendment 3: tobacco tax campaign. Washington University in St. Louis, Center for Tobacco Policy Research. 2008.

35. Center for Tobacco Policy Research. Show me health: clearing the air about tobacco-final evaluation report. Washington University in St. Louis, Center for Tobacco Policy Research. 2007. 